\title{
Mangiferin: An effective therapeutic agent against several disorders (Review)
}

\author{
SUYA DU ${ }^{1 *}$, HUIRONG LIU ${ }^{2 *}$, TIANTIAN LEI ${ }^{3 *}$, XIAOFANG XIE ${ }^{3 *}$, \\ HAILIAN WANG ${ }^{2}, \mathrm{XIA} \mathrm{HE}^{4}$, RONGSHENG TONG ${ }^{4}$ and YI WANG ${ }^{4}$ \\ ${ }^{1}$ Department of Pharmacy, Chengdu Military General Hospital, Chengdu, Sichuan 610083; \\ ${ }^{2}$ Institute of Organ Transplantation, Sichuan Academy of Medical Science and Sichuan Provincial People's Hospital, \\ Chengdu, Sichuan $610072 ;{ }^{3}$ School of Medicine, University of Electronic Science and Technology of China, \\ Chengdu, Sichuan 610054; ${ }^{4}$ Personalized Drug Therapy Laboratory of Sichuan Province, Department of Pharmacy, \\ Sichuan Academy of Medical Science and Sichuan Provincial People's Hospital, Chengdu, Sichuan 610072, P.R. China
}

Received February 9, 2018; Accepted August 20, 2018

DOI: $10.3892 / \mathrm{mmr} .2018 .9529$

\begin{abstract}
Mangiferin (1,3,6,7-tetrahydroxyxanthone-C2- $\beta$-Dglucoside) is a bioactive ingredient predominantly isolated from the mango tree, with potent antioxidant activity and multifactorial pharmacological effects, including antidiabetic, antitumor, lipometabolism regulating, cardioprotective, anti-hyperuricemic, neuroprotective, antioxidant, anti-inflammatory, antipyretic, analgesic, antibacterial, antiviral and immunomodulatory effects Therefore, it possesses several health-endorsing properties and is a promising candidate for further research and development. However, low solubility, mucosal permeability and bioavailability restrict the development of mangiferin as a clinical therapeutic, and chemical and physical modification is required to expand its application. This review comprehensively analyzed and collectively summarized the primary pharmacological actions of mangiferin that have been demonstrated in the literature, to support the potential future development of mangiferin as a novel therapeutic drug.
\end{abstract}

\section{Contents}

1. Introduction

2. Potential application of mangiferin in antidiabetic therapy

3. Anti-tumor effects of mangiferin

Correspondence to: Dr Yi Wang or Dr Rongsheng Tong, Personalized Drug Therapy Laboratory of Sichuan Province, Department of Pharmacy, Sichuan Academy of Medical Science and Sichuan Provincial People's Hospital, 32 West First Ring Road, Chengdu, Sichuan 610072, P.R. China

E-mail:w_yi@yahoo.com

E-mail: tongrs@126.com

*Contributed equally

Key words: mangiferin, pharmacological activities, bioactive compound, structural modification
4. The neuroprotective properties of mangiferin

5. Cardiovascular effects of mangiferin

6. Other properties of mangiferin

7. Conclusions

\section{Introduction}

Mangiferin, a C-glucosyl xanthone with the formula 1,3,6,7-tetrahydroxyxanthone-C2- $\beta$-D-glucoside (Fig. 1), has been extensively studied both in vivo and in vitro. It has been demonstrated to possess numerous pharmacological activities, including antioxidative, antiaging, antitumor, antibacterial, antiviral, immunomodulatory, antidiabetic, hepatoprotective and analgesic effects (1-3). Mangiferin has been detected in many plant species and may be abundantly isolated from various parts of Mangiferaindica (mango), including the leaves, stem bark, fruit peels and root $(4,5)$.

With advances in pharmacology and molecular biology, research regarding mangiferin has increased and more pharmacological mechanisms have been revealed, which provides further information for the design and development of mangiferin as a clinical therapeutic. However, Wang et al (6) reported that the solubility of mangiferin was only $0.111 \mathrm{mg} / \mathrm{ml}$. In addition, Han et al (7) demonstrated that the oral bioavailability of mangiferin was only $1.2 \%$. This may be due to its low lipophilicity properties, poor intestinal membrane permeability and low oral absorption (8). These experimental data collectively indicate that despite a wide range of pharmacological activities, mangiferin has low solubility, transmembrane permeability and bioavailability, which restricts the clinical development and application of mangiferin. In order to identify more effective therapeutic compounds, mangiferin derivatives with improved solubility, bioavailability and potency were obtained by chemical or biotransformation methods (9). Therefore, with the progress of biotechnology and research practice, mangiferin may be identified to represent a more promising, novel therapeutic drug in clinic.

Based on previous studies concerning the structural modification, pharmacological activities and therapeutic molecular 
mechanisms of mangiferin in recent decades, the pharmacological effects of mangiferin were reviewed herein, in order to provide references for further drug research and development.

\section{Potential application of mangiferin in antidiabetic therapy}

Prevalence and main features of diabetes mellitus. Diabetes mellitus is a common endocrine and metabolic disease that affects public health and quality of life $(10,11)$. Statistics from the International Diabetes Federation Diabetes Atlas (http://www.diabetesatlas.org/resources/2017-atlas. $\mathrm{html}$ ) revealed that there were an estimated 425 million adult patients with type 2 diabetes (T2D) in 2017, of whom 212 million were not diagnosed (12). Notably, China has the largest number of adult diabetic patients. The prevalence of diabetes and prediabetes in China is 11.6 and $50.1 \%$, respectively, accounting for 113.9 million patients with diabetes and 493.4 million individuals with prediabetes, according to China's non-communicable disease surveillance group in 2013 (13). These data indicate that diabetes has become a major public health problem worldwide.

The main feature of diabetes is hyperglycemia, which is caused by disrupted glucose homeostasis $(14,15)$. $\beta$-cell deficiency in the pancreas results in insufficient insulin secretion and type 1 diabetes, whereas insulin resistance may lead to decreased insulin sensitivity in T2D. Glucose homeostasis requires coordinated regulation of the pancreas and insulin target organs, such as adipose tissue, muscle, the liver and the brain (15). In the pancreas, $\alpha$ cells secrete glucagon and $\beta$ cells secrete insulin, which respond to blood glucose alterations. High glucose stimulates insulin secretion, which increases glucose uptake, use and storage in adipose and muscle tissue. Low glucose stimulates glucagon release, which promotes hepatic glucose production in the liver to increase the blood glucose levels (16). Fat cells release adipokines, including leptin, adiponectin and cytokines, as well as free fatty acids (FFA) to regulate food intake, insulin secretion and insulin sensitivity (17). The interaction between various organs or tissues associated with blood glucose regulation is essential. Disordered regulation of this system may lead to the occurrence of diabetes (18). Patients with type 1 and T2D may have progressive complications, including heart disease, stroke, blindness, diabetic nephropathy and kidney failure (19-22), if the disease is not effectively controlled. Therefore, it is necessary prevent and treat diabetes in the early stage.

Effect of mangiferin on diabetes and diabetic complications. Although drugs with multiple pharmacological mechanisms are the most effective regimens to alleviate the effects of type 2 diabetes, they cannot completely prevent disease progression $(23,24)$. Therefore, novel and effective drugs are urgently needed. It was recently reported that mangiferin treatment was beneficial in streptozotocin (STZ)-induced diabetic mice. Biochemical, toxicological and hematological parameters were evaluated following oral treatment with $40 \mathrm{mg} / \mathrm{kg}$ mangiferin for 30 days. Compared with diabetic control mice, the levels of blood glucose, glycosylated hemoglobin, aspartate aminotransferase (AST), alanine aminotransferase (ALT) and alkaline phosphatase (ALP) were significantly reduced in mangiferin-treated diabetic mice. Furthermore, the levels of red and white blood cells were notably improved $(25,26)$. Therefore, mangiferin was demonstrated to possess anti-diabetic efficacy without toxicity in chemically induced diabetic mice (Fig. 2A). Additionally, in a high-fat high fructose diet and STZ-induced diabetic insulin-resistant rat model, mangiferin was demonstrated to concurrently alleviate insulin resistance, improve $\beta$-cell function, reduce serum levels of triglyceride (TG), total cholesterol (TC) and low-density lipoprotein cholesterol (LDL-C), as well decrease the atherogenic index, liver TG and liver TC content. Liver glycogen content was also enhanced (27). These results validated that mangiferin may effectively improve insulin sensitivity in the treatment of type 2 diabetes accompanied with metabolic disorders (Fig. 2B). Similarly, Muruganandan et al (28), Miura et al $(29,30)$ and Suman et al (31) verified that mangiferin exerted significant antidiabetic, antihyperlipidemic and antiatherogenic effects in diabetic rat models. As for the promotion of islet function induced by mangiferin, our previous study performed $70 \%$ partial pancreatectomy (PPx) in mice to elucidate the antidiabetic mechanisms of mangiferin. The results indicated that mangiferin facilitates $\beta$-cell proliferation and islet regeneration through the regulation of crucial genes in cell cycle and islet regeneration (Fig. 2C) (32). Furthermore, our upcoming report successfully confirmed that mangiferin increases islet regeneration in young and old diabetic mice (unpublished data). Taken together, these data provide evidence that mangiferin has promising application prospects in the treatment of diabetes.

As one of the most common and serious diabetic complications, diabetic nephropathy (DN) is a renal impairment caused by diabetes-induced microangiopathy and glomerulosclerosis. Hypertension, proteinuria and hydropsy are the clinical manifestations of DN (33). Surprisingly, Pal et al (34) demonstrated that mangiferin could protect kidneys from DN. They investigated the specific mechanisms underlying the protective effects of mangiferin in a STZ-induced diabetic nephropathy rat model and observed that mangiferin markedly decreased plasma glucose, kidney to body weight ratio, blood urea nitrogen (BUN), plasma creatinine, uric acid and urinary albumin. Additionally, glomerular hypertrophy and hydropsy was attenuated following mangiferin treatment at an oral dose of $40 \mathrm{mg} / \mathrm{kg}$ body weight/day in water for 30 days (34). Similarly, in animal experiments performed by Liu et al (35) in an STZ-induced DN rat model, evidential decreases in albuminuria, BUN, kidney weight index, periodic acid-Schiff stain positive mesangial matrix area, glomerular extracellular matrix expansion and accumulation and glomerular basement membrane thickness were observed following oral mangiferin treatment $(15,30$ and $60 \mathrm{mg} / \mathrm{kg})$ for 9 weeks, via targeting of glyoxalase 1 . These results validate the beneficial actions of mangiferin in DN, although body weight and blood glucose levels were not improved (35). Furthermore, mangiferin (15, 30 and $60 \mathrm{mg} / \mathrm{kg} /$ day for 9 weeks) effectively attenuated renal fibrosis through the inhibition of osteopontin overproduction and inflammation in a STZ-induced rat diabetic model (36).

Cardiovascular events may also occur in patients with T2DM, including stroke, myocardial infarction and endothelial dysfunction, which are major physical and economic burdens (37-39). Hyperglycemia-induced oxidative stress and 


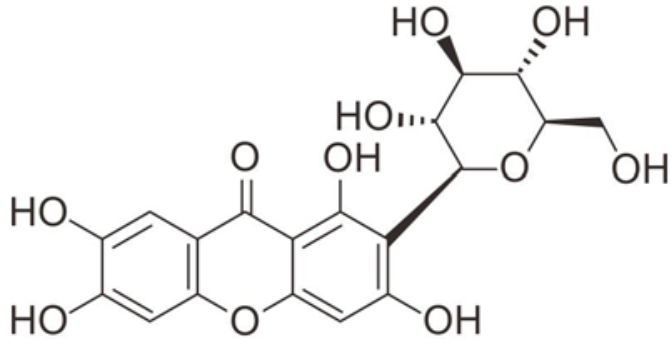

Figure 1. Chemical structure of mangiferin.

inflammation are thought to be involved in the development of cardiovascular disease. The activation of advanced glycation end products-receptor for advanced glycation end products (AGE-RAGE) results in increased oxidative stress, inflammation and apoptosis in ischemia-reperfusion (IR)-induced myocardial injury in diabetic rats (40). Notably, mangiferin inhibits activation of the AGE-RAGE/mitogen-activated protein kinase (MAPK), c-Jun N-terminal kinase (JNK) and p38 pathways (41). The expression of extracellular regulated kinase $1 / 2$ (ERK1/2) in the myocardium is also increased (41). In addition, chronic treatment with mangiferin $(20 \mathrm{mg} / \mathrm{kg}$ for 16 weeks) decreased the level of myocardial enzymes creatine kinase-MB and lactate dehydrogenase (LDH), as well as the inflammatory mediators tumor necrosis factor (TNF)- $\alpha$ and interleukin (IL)-1 $\beta$ in the serum and left ventricular myocardium (41). In diabetic cardiomyopathy (DCM) rats, mangiferin reduces AGE production, and decreases the mRNA and protein expression of RAGE (42), suggesting that mangiferin treatment may be beneficial in DCM. A previous study determined the effect of mangiferin on myocardial IR injury in diabetic rats and further investigated the underlying mechanisms involved in its cardioprotective effects. In a diabetic rat model induced by STZ, mangiferin $(60 \mathrm{mg} / \mathrm{kg}$; oral gavage for 12 weeks) reduces blood glucose and cardiomyocyte apoptosis, downregulates inositol-requiring enzyme 1, apoptotic signal-regulating kinase and JNK (43). This suggests that mangiferin inhibits the apoptosis of myocardial cells in diabetic rats via mechanisms associated with blood glucose regulation and endoplasmic reticulum (ER) stress prevention. Endothelial dysfunction, under conditions of ER stress and increased reactive oxygen species (ROS) production, is tightly associated with cardiovascular complications in diabetes (44). The expression of thioredoxin-interacting protein (TXNIP), NLR family pyrin domain containing 3 (NLRP3), IL-1 $\beta$ and IL-6, as well as the phosphorylation of AMP-activated protein kinase (AMPK), was attenuated in endothelial cells cultured with mangiferin at concentrations of $0.1,1$ and $10 \mu \mathrm{M}$, demonstrating its inhibitory effects on TXNIP/NLRP3 inflammasome activation and it ameliorative effects on endothelial dysfunction (45).

\section{Anti-tumor effects of mangiferin}

The research and development of antitumor agents with fewer adverse effects has become a popular topic of research. As a monomer of traditional Chinese medicine, mangiferin has been demonstrated to have direct and auxiliary roles in oncotherapy. Mangiferin efficaciously inhibits tumor cell cycle progression. It has been widely accepted that cell growth prior to cell division is strictly controlled by the cyclin-dependent kinase 1 (CDK1)/cyclin B1 complex (46-48). Notably, mangiferin has been validated to trigger $\mathrm{G} 2 / \mathrm{M}$ phase cell cycle arrest via regulation of the CDK1-cyclin B1 signaling pathway (49-51). DNA synthesis is accomplished during the $\mathrm{S}$ phase of the cell cycle, and treatment with mangiferin causes S phase delay in colorectal cancer HT29 cells and cervical cancer HeLa cells (52). In addition to its inhibitory actions on cell cycle, mangiferin induces apoptosis in tumor cells. Nuclear factor- $\kappa \mathrm{B}(\mathrm{NF}-\kappa \mathrm{B})$ is a transcription factor that induces the proliferation of cancer cells (53). RelA and RelB, important members of NF- $\kappa \mathrm{B}$ family, are transformed into activated $\mathrm{NF}-\kappa \mathrm{B}$ following dimerization. It was demonstrated that mangiferin inhibits the expression of RelA and RelB, activates inhibitor of NF- $\kappa$ B (I $\kappa$ B) and suppresses the phosphorylation of $N F-\kappa B$ kinase, thereby inhibiting the transcriptional activity of $\mathrm{NF}-\kappa \mathrm{B}$ and inducing

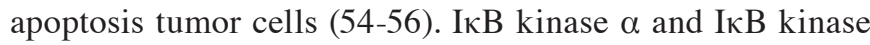
$\beta$-dependent $\mathrm{I} \kappa \mathrm{B}$ degradation and subsequent NF- $\kappa \mathrm{B}$ activation have been widely acknowledged as the canonical $\mathrm{NF}-\kappa \mathrm{B}$ activation pathway (57). However, a collective patent review on mangiferin unveiled that multiple signaling pathways, including nuclear $\mathrm{NF}-\kappa \mathrm{B}$ signaling and cyclooxygenase-2 (COX-2) protein expression are involved in the antitumor effects of mangiferin (56). This patent review concluded that mangiferin is a candidate molecule in the development of novel antitumor drugs. Furthermore, caspase activation may participate in the apoptosis-inducing effects of mangiferin in oncotherapy. A disturbance in the balance between cell proliferation and apoptosis is known to initiate tumorigenesis (58). Caspase activation serves a critical role in apoptosis, particularly via the mitochondria-initiated pathway (59). Pan et al (60) demonstrated that through regulation of Bcl-2, apoptosis regulator (Bcl-2) and $\mathrm{Bcl}-2$ associated $\mathrm{X}$, apoptosis regulator (Bax) expression, mangiferin potently inhibits tumor cell proliferation and induces apoptosis in nasopharyngeal carcinoma cells. Additionally, a study of the antitumor efficacy and underlying mechanisms of mangiferin in human cervical carcinoma HeLa cells demonstrated that the protein expression of $\mathrm{BH} 3$ interacting domain death agonist, Bcl-2 and pro-caspase- 3 and -8 is downregulated in response to mangiferin treatment, which results in the activation of caspase-3, $-7,-8$ and -9 , ultimately leading to apoptosis (61).

Our previous studies contributed to the understanding of the underling molecular mechanism of mangiferin in oncotherapy $(55,62,63)$. In human breast carcinoma MCF-7 cells, mangiferin down regulates the cyclin-dependent kinase 1-cyclin Bl signaling pathway and induces G2/M phase cell-cycle arrest to inhibit tumor cell growth (62). In addition, it was demonstrated to inhibit the protein kinase $\mathrm{C}$ (PKC)-NF- $\kappa$ B pathway to induce apoptotic cell death (62). Furthermore, in vivo experiments performed in a MCF-7 xenograft rat model confirmed the in vitro results (62). Similarly, in human lung carcinoma A549 cells, mangiferin exhibits antineoplastic properties, by inducing G2/M phase cell cycle arrest via downregulation of the cyclin-dependent kinase 1-cyclin B1 signaling pathway and inducing apoptotic cell death by inhibiting the PKC-NF- $\kappa \mathrm{B}$ pathway (55). In addition, in-depth research into the underlying mechanisms of mangiferin successfully elucidated that caspase-dependent 

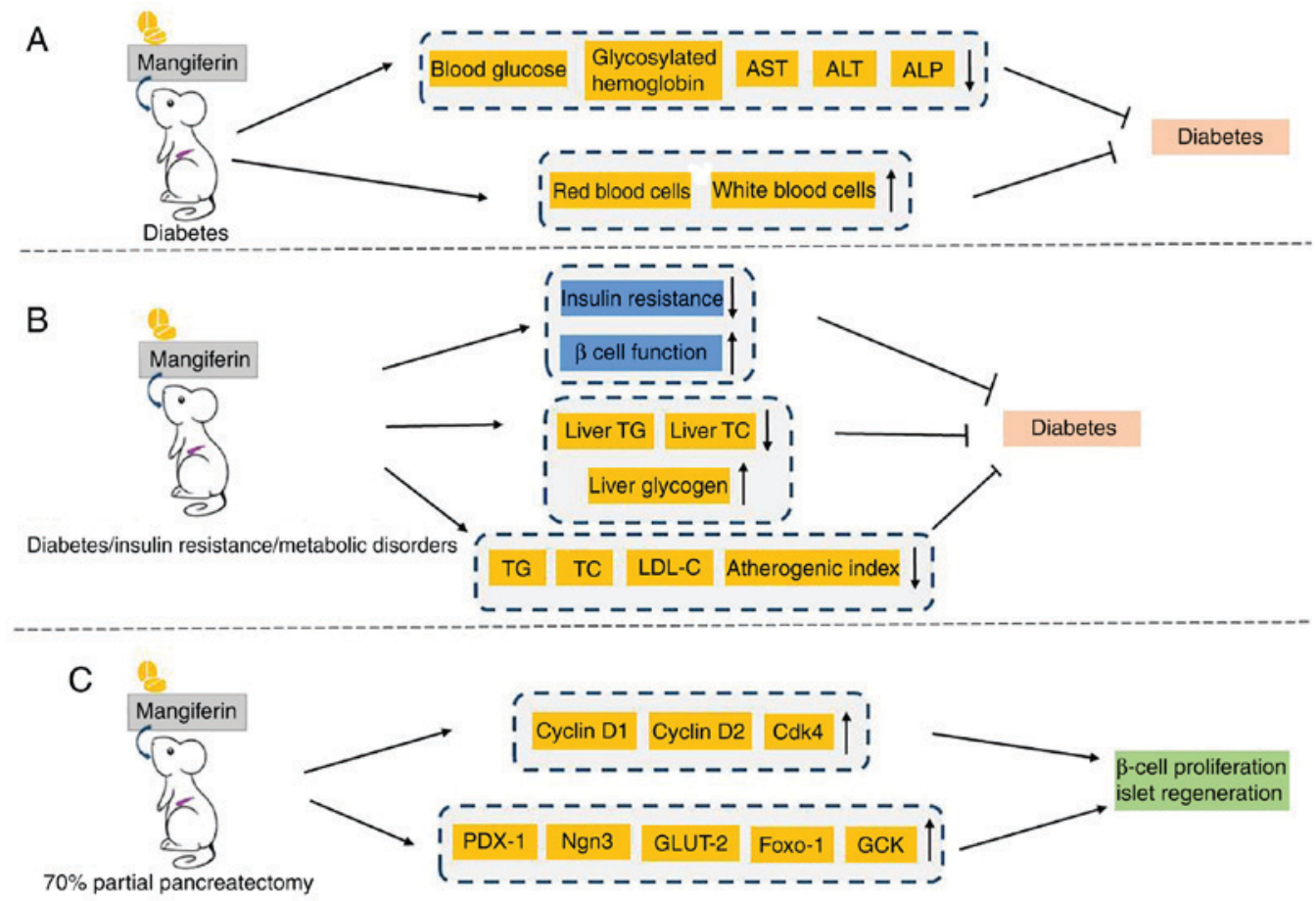

Figure 2. Overview of the functions of mangiferin in diabetes mellitus. (A) A significant reduction of biochemical and toxicological parameters, as well as a marked improvement in hematological parameters were simultaneously observed in diabetic rats. (B) Mangiferin notably increased insulin sensitivity and $\beta$ cell function, and improved parameters associated with metabolic disorders. (C) Mangiferin regulated the expression of genes involved in cell cycle regulation and islet regeneration to improve islet function. AST, aminotransferase; ALT, alanine aminotransferase; ALP, alkaline phosphatase; TG, triglyceride; TC, total cholesterol; LDL-C, low density lipoprotein cholesterol; Cdk4, cyclin-dependent kinase 4; PDX-1, pancreatic and duodenal homeobox 1; Ngn3, neurogenin 3; GLUT-2, glucose transporter 2; Foxo-1, forkhead box protein O1; GCK, glucokinase.

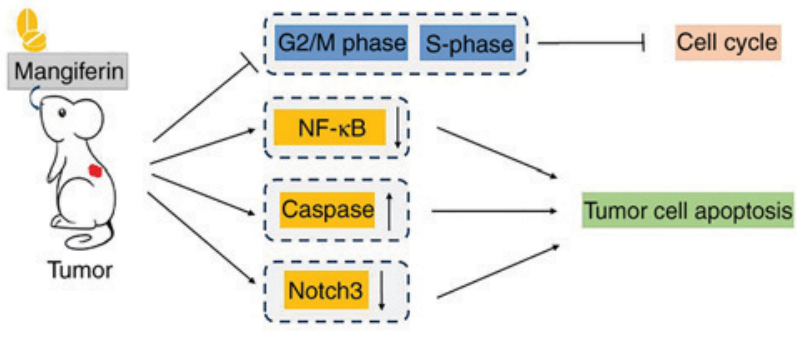

Figure 3. Schematic of the molecular mechanisms underlying the antitumor effects of mangiferin. NF- $\kappa \mathrm{B}$, nuclear factor- $\kappa \mathrm{B}$.

apoptosis and obviously downregulated Notch3 expression occurs in mangiferin-treated human ovarian adenocarcinoma OVCAR3 cells (63). Based on these previous studies, it may be concluded that mangiferin exhibits prominent anti-tumor action in certain malignant neoplasms through multifactorial molecular mechanisms (Fig. 3).

\section{The neuroprotective properties of mangiferin}

Abundant research on the effects of mangiferin has revealed the antioxidant and anti-inflammatory properties, due to its C-glycosylxanthone structure (64). The C-glucosy 1 linkage and polyhydroxy component in mangiferin contributes to its free radical-scavenging activity (65). Free radicals are highly reactive molecules that are implicated in the pathology of traumatic brain injury and cerebral ischemia through oxidative stress and inflammation (66-68). In recent decades, the role of free radicals in the pathology of traumatic brain injury and cerebral ischemia has been elucidated by investigating oxidative stress and inflammation with other pathogenic processes, such as excitotoxicity, calcium overload, mitochondrial cytochrome c release, caspase activation and apoptosis in trauma and ischemia of central nervous system (CNS) (69). Furthermore, mangiferin is capable of modulating the expression of proinflammatory signaling molecules, including the expression of TNF- $\alpha$ and COX-2, as well as regulating various transcription factors, such as NF- $\mathrm{kB}$, and NF-E2-related factor 2 (Nrf-2) (64). Research regarding the protective effects of mangiferin in CNS injury, proinflammatory cytokine expression, oxidative stress and neurobehavioral abnormalities induced by lipopolysaccharide (LPS) in cerebrum are detailed herein.

Accumulating evidence has revealed that mangiferin is able to attenuate LPS-induced cognitive deficits caused by neuroinflammation (70). Oral mangiferin pre-treatment $(50 \mathrm{mg} / \mathrm{kg})$ and treatment $(50 \mathrm{mg} / \mathrm{kg}$ ) following LPS injection in mice demonstrated that mangiferin ameliorates cognitive deficits by decreasing LPS-induced IL-6 expression and increasing heme oxygenase-1 (HO-1) expression in mice hippocampi. Similarly, in behavioral experiments, mice were treated with LPS $(0.83 \mathrm{mg} / \mathrm{kg})$ intraperitoneal injection following oral pretreatment with mangiferin (20 and $40 \mathrm{mg} / \mathrm{kg}, 14$ days), which subsequently attenuated depressive and anxiety-like behaviors (71). Further research has ascertained that mangiferin increases glutathione concentration, superoxide dismutase (SOD) and catalase activity in mice; as well as decreasing lipid peroxidation and nitrite level in the hippocampus and prefrontal cortex (71). Furthermore, mangiferin reduces LPS-induced 


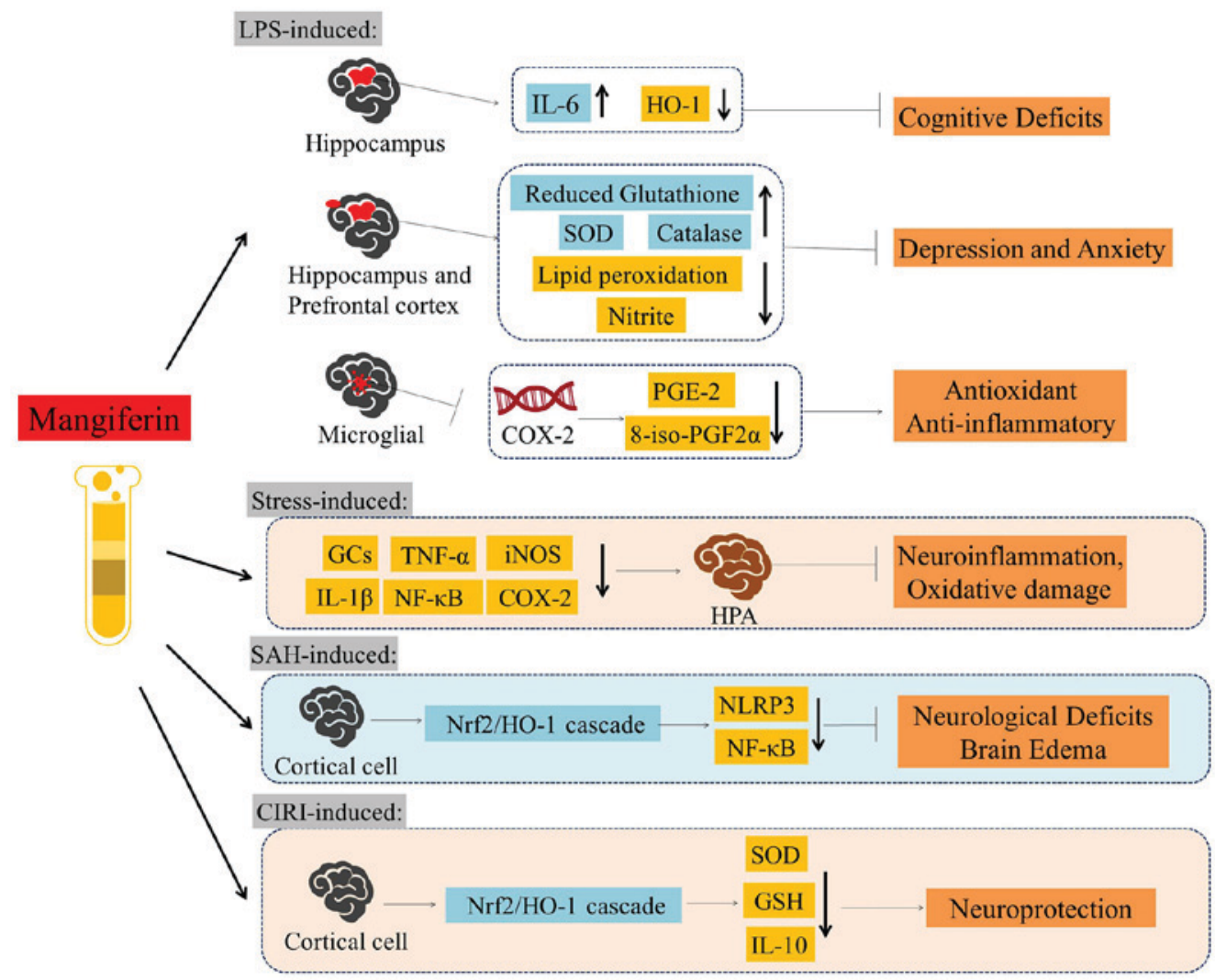

Figure 4. Overview of the neuroprotective activities of mangiferin against LPS-, stress-, SAH- and CIRI-induced models. Mangiferin has been demonstrated to exert protective effects against cognitive deficits, depression, anxiety, neuroinflammation, oxidative damage, neurological deficits and brain edema. LPS, lipopolysaccharide; SAH, subarachnoid hemorrhage; CIRI, cerebral ischemia reperfusion injury; IL, interleukin; HO-1, heme oxygenase-1; SOD, superoxide dismutase; PGE-2, prostaglandin E2; 8-iso-PGF2 $\alpha$, 8-iso-prostaglandin F2 $\alpha$; GCs, glucocorticoids; TNF- $\alpha$, tumor necrosis factor- $\alpha$; iNOS, inducible nitric

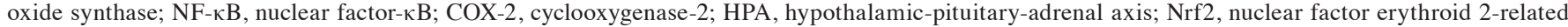
factor 2; NLRP3, NLR family pyrin domain containing 3; GSH, glutathione.

IL-1 $\beta$ expression and oxidative stress when used in depressive and anxiety disorders (71). Therefore, these studies indicated that mangiferin greatly contributes to cerebral protection. By decreasing COX-2 transcript stability, mangiferin potently reduces LPS-induced prostaglandin E2 (PGE-2) synthesis and 8 -iso-prostaglandin F2 $\alpha$ (8-iso-PGF2 $\alpha$ ) production (72). Taken together, these data demonstrated mangiferin exhibits potent antioxidant and anti-inflammatory properties, by decreasing PGE-2 production, free radical formation and COX-2 synthesis.

The underlying mechanisms of neuroinflammation and oxidative damage in the brain are complicated. Young adult male Wistar rats were exposed to a high-stress environment and neurological and neuropsychiatric diseases associated with cell damage and apoptosis were observed in their cerebrum, such as neurodegenerative diseases, depression, and schizophrenia (73). It was demonstrated that mangiferin administration $(15,30$ and $60 \mathrm{mg} / \mathrm{kg}$; oral gavage) prevents hypothalamic/pituitary/adrenal (HPA) stress axis dysregulation, neuroinflammation and oxidative damage. Pretreatment with mangiferin inhibits an increase in the levels of glucocorticoids (GCs), IL-1 $\beta$, TNF- $\alpha$, TNF receptor 1, NF- $\kappa \mathrm{B}$, inducible nitric oxide synthase (iNOS) and COX-2 (73). Furthermore, mangiferin effectively protects against early brain injury (EBI) that is involved in the process of cerebral tissue damage induced by subarachnoid hemorrhage (SAH) (74). It was demonstrated that mangiferin decreases the mortality of animals with SAH, ameliorates neurological deficits and brain edema, attenuates SAH-induced oxidative stress and decreases cortical cell apoptosis in a dose-dependent manner. Mechanism analysis of mangiferin demonstrated that it exerts its neuroprotective effects against EBI by promoting the nuclear factor erythroid 2-related factor 2 (Nrf2)/HO-1 cascade in the mitochondrial apoptosis pathway, as well as through NLRP3 inflammasome activation and NF- $\kappa \mathrm{B}$ inhibition (74). In addition, in Wistar male rats with cerebral IR injury, the activation of Nrf2/HO-1 cascade is promoted in a dose-dependent manner by mangiferin (75). Furthermore, mangiferin ameliorates the activities of SOD, glutathione and IL-10, which has a protective role in oxidative stress induced by cerebral IR injury (Fig. 4).

\section{Cardiovascular effects of mangiferin}

Cardioprotective effects of mangiferin. Increasing amounts of evidence regarding the cardioprotective effects of mangiferin in isoproterenol (ISPH)-induced myocardial infarction (MI) rats has emerged. Prabhu et al (76) demonstrated that pretreatment with mangiferin $(100 \mathrm{mg} / \mathrm{kg})$ for 28 days regulates the tissues defense system against cardiac damage. Specifically, the activities of heart tissue enzymic antioxidants, including superoxide dismutase, catalase, glutathione peroxidase, 
glutathione transferase and glutathione reductase, as well as non-enzymic antioxidants such as cerruloplasmin, Vitamin C, Vitamin E and glutathione, were all notably upregulated (76). It was concluded that mangiferin exerts its beneficial effects due to its antioxidant potential, which reduces myocardial oxygen consumption and relieves angina pectoris (76). In addition, mangiferin protects the myocardium against ISPH-induced MI by reducing lipid peroxide formation and retaining the activities of myocardial marker enzymes, including $\mathrm{LDH}$, creatine phosphokinase (CPK), AST and ALT (77). Those results suggested that mangiferin effectively alleviates free radical release in the ischemic myocardium and delays membrane lipid oxidation. In addition, studies in myocardial cells under the condition of ISPH-induced MI demonstrated mangiferin protects the structural integrity of by reducing the effects of oxidative damage and increasing mitochondrial energy metabolism (78). Mangiferin markedly increases the activities of the tricarboxylic acid cycle and antioxidant defense enzymes in MI (78). In addition, mangiferin has been reported to prevent free radical-mediated lipid peroxidation and increase lysosomal instability, thus alleviating MI injury (79).

It has also been demonstrated that mangiferin improved heart blood flow parameters and fiber disturbance in a dose-dependent manner, following a single intravenous injection of mangiferin $(5,10$ or $20 \mathrm{mg} / \mathrm{kg})$ in a MI experimental model (80). Mangiferin administration ( $20 \mathrm{mg} / \mathrm{kg}$ for 4 weeks) restores the function of cardiac ejection, reduces the accumulation of TNF- $\alpha$ and cleaved caspase-3, and upregulates Bcl-2 (80). In addition, mangiferin has a therapeutic effect on post-MI left ventricular remodeling and improves cardiac function. Mangiferin administration (50 or $100 \mathrm{mg} / \mathrm{kg}$ for 5 weeks) also protects against doxorubicin-induced mortality and electrocardiogram abnormality, decreases the expression of biochemical cardiac toxicity markers, such as dehydrogenase and creatine phosphokinase isoenzyme (81). Histopathologically, mangiferin treatment results in obvious reductions in inflammatory cell number, fibrotic area and necrotic foci (81), which indicates that mangiferin may have a preventive effect against ventricular hypertrophy and fibrosis induced by MI. Therefore, mangiferin may be used in combination with clinical treatments in the future, including with surgery or other therapeutics (Fig. 5A).

Mangiferininatherosclerosis andhyperlipemia.Hyperlipidemia and elevated FFAs are risk factors for atherosclerosis, hyperlipemia and cardiovascular disease (82). Therefore, research into the effects of mangiferin on abnormal lipid metabolism in the cardiovascular system is increasing (Fig. 5B). Atherosclerosis is closely associated with abundant oxidative events, including low-density lipoprotein (LDL) oxidation and increased intracellular reactive ROS production. Mangiferin is a polyphenol compound extracted from mango leaves and is the main active ingredient of food supplement of the flood supplement VIMANG, which is widely popular in Cuba (83). VIMANG is extracted from the bark of Mangiferaindica and is typically administered as a tablet, containing $300 \mathrm{mg}$ of mango bark extract (83). Oral supplementation with VIMANG, or its main polyphenol mangiferin, markedly reduces ROS generation in isolated LDL receptor (-/-) liver mitochondria and spleen lymphocytes (84). In addition, treatment prevents mitochondrial nicotinamide-adenine dinucleotide phosphate hydrate (NADPH)-linked substrate depletion and NADPH spontaneous oxidation, making them suitable antioxidants with potential use in atherosclerosis susceptible conditions (84).

Guo et al (85) discovered that mangiferin (50 and $150 \mathrm{mg} / \mathrm{kg}$ ) ameliorates hypertriglyceridemia by modulating the expression of genes involved in lipid oxidation and lipogenesis. Body weight, liver weight, visceral fat-pad weight, serum TG, FFA concentration, hepatic TG levels, hepatic FFA and muscle FFA contents are immensely decreased following mangiferin treatment (85). It was observed that mangiferin upregulates the mRNA levels of peroxisome proliferator-activated receptor- $\alpha$, fatty acid translocase (CD36) and carnitine palmitoyl transferase 1 (CPT-1) (86). Wistar rats were fed a high-fat diet and administered mangiferin $(50,100,150 \mathrm{mg} / \mathrm{kg})$ simultaneously for 6 weeks, which confirmed that mangiferin improves FFA metabolism in a dose-dependent manner through promoting FFA uptake and oxidation (86). Similarly, it was also observed in Wistar rats and HepG2 cells that levels of intracellular FFA and TG accumulation was decreased in HepG2 cells. Furthermore, the AMPK pathway is associated with this therapeutic effect of mangiferin (86). Mangiferin increases the AMP/ATP ratio upstream of AMPK, decreases acyl-CoA:diacyl gycerol acyltransferase 2 (DGAT2) expression, decreases acetyl-CoA carboxylase (ACC) activity. Furthermore, mangiferin promotes AMPK phosphorylation, and upregulates the expression of CD36 and CPT-1 (86). Based on the preliminary results of cell and animal experiments, $\mathrm{Na}$ et al (87) conducted a 12-week double-blind randomized clinical trial to evaluate the effects of mangiferin $(150 \mathrm{mg} /$ day $)$ on blood lipid profiles in overweight patients with hyperlipidemia. Mangiferin supplementation substantially increases the serum levels of mangiferin, high-density lipoprotein cholesterol, L-carnitine, $\beta$-hydroxybutyrate and acetoacetate, and increases lipoprotein lipase activity. However, mangiferin did not effectively decrease serum levels of total cholesterol, low-density lipoprotein cholesterol, serum glucose or insulin (87).

Apontes et al (88) administered mangiferin $(400 \mathrm{mg} / \mathrm{kg})$ and a high fat diet (HFD) to C57BL6/J mice for 16 weeks, demonstrating that mangiferin protects against HFD-induced weight gain, promotes aerobic mitochondrial capacity and increases thermogenesis. In addition, treatment with mangiferin in overweight patients with hyperlipidemia stimulated carbohydrate oxidation and improved glucose and insulin profiles (88). The activity of mangiferin on lipogenesis regulation was further studied by proteomic analysis, in which C57BL6/J mice were fed mixed granules containing mangiferin and HFD for 18 weeks. It was demonstrated that out of 865 quantified proteins, 87 of them are differentially regulated by mangiferin. Of these proteins, $\sim 50 \%$ are involved in energy metabolism and metabolite biosynthesis. Further classification indicated that mangiferin increases the expression of proteins that are crucial for mitochondrial biogenesis and oxidative activity, including oxoglutarate dehydrogenase E1 and cytochrome c oxidase subunit 6B1. In addition, mangiferin decreases the expression of proteins that are critical for lipogenesis, including fatty acid stearoyl-CoA desaturase 1 and acetyl-CoA carboxylase 1 (89). Taken together, these data suggest that mangiferin may be used in the treatment of metabolic disorders, by improving the protein expression profiles in mitochondrial synthesis and lipogenesis. 

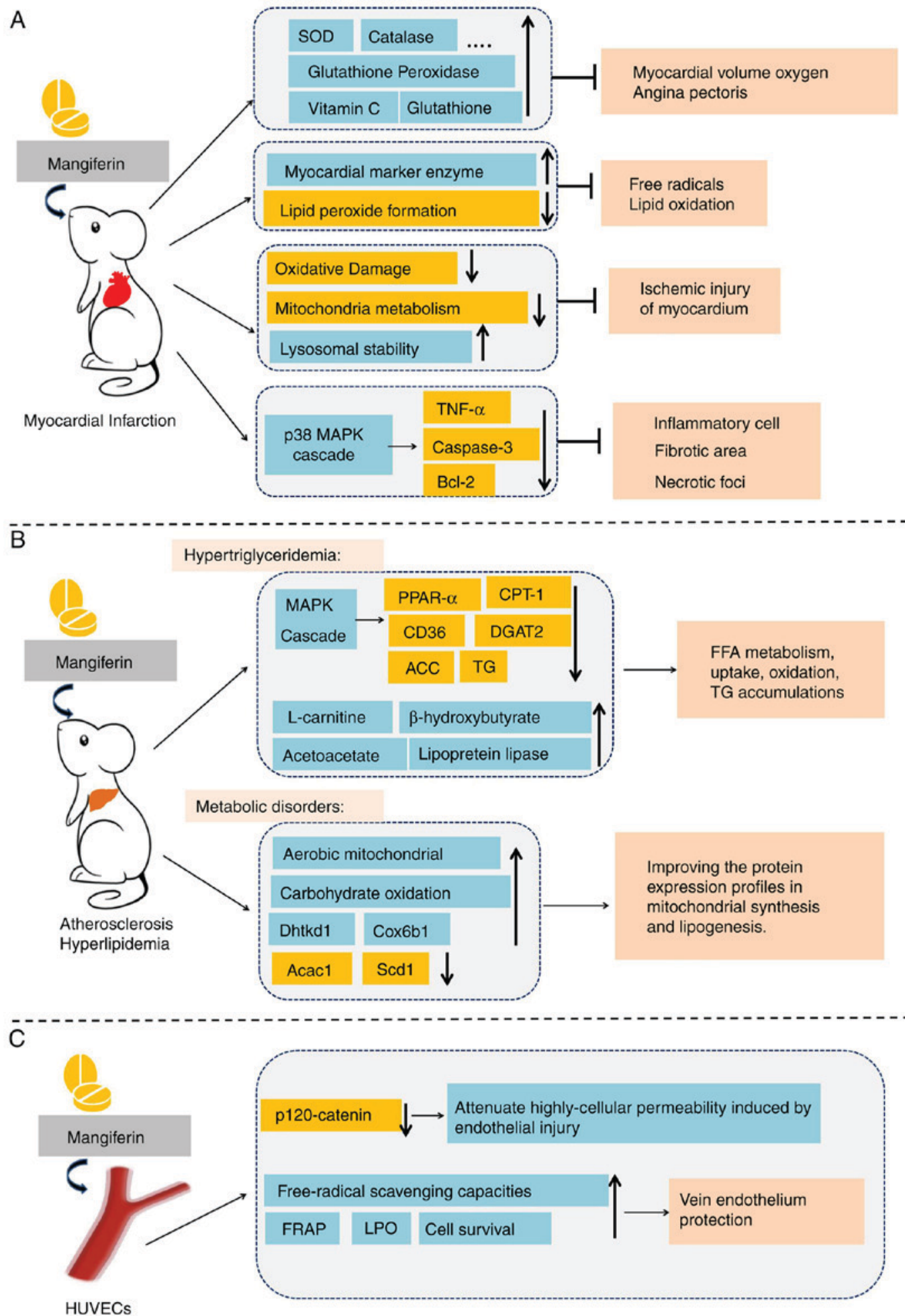

Figure 5. Potential effects of mangiferin in cardiovascular disease. (A) Mangiferin exhibited marked cardioprotective effects in ISPH-induced myocardial infarction rat models. (B) Mangiferin alleviated lipometabolic abnormalities in the cardiovascular system. (C) Mangiferin protected vascular endothelium function. SOD, TNF- $\alpha$, Bcl-2, PPAR- $\alpha$, peroxisome proliferator-activated receptor- $\alpha$; CPT-1, carnitine palmitoyltransferase 1; DGAT2, diacylglycerol O-acyltransferase 2; ACC, acetyl-CoA carboxylase; TG, triglyceride; FFA, free fatty acid; Dhtkd1, dehydrogenase E1 and transketolase domain containing 1; Cox6b1, cytochrome C oxidase subunit 6B1; Acac1, acetyl-CoA carboxylase 1; Scd1, stearoyl-CoA desaturase 1; FRAP, ferric reducing ability of plasma; LPO, lipid peroxidation.

Mangiferin in vein endothelium. The abnormal structure and function of vascular endothelial cells are the pathological basis of many cardiovascular diseases, and vascular endothelial cells are vulnerable to a series of harmful factors (90). Under the stimulation of high blood pressure, oxidative stress and high levels of blood glucose/lipids, vascular endothelial cells synthesize and release vasodilator factors and vasoconstrictor factors, which have important roles in vascular homeostasis, thrombosis and inflammation (91). In recent decades, the protective effects of mangiferin on human umbilical vein 


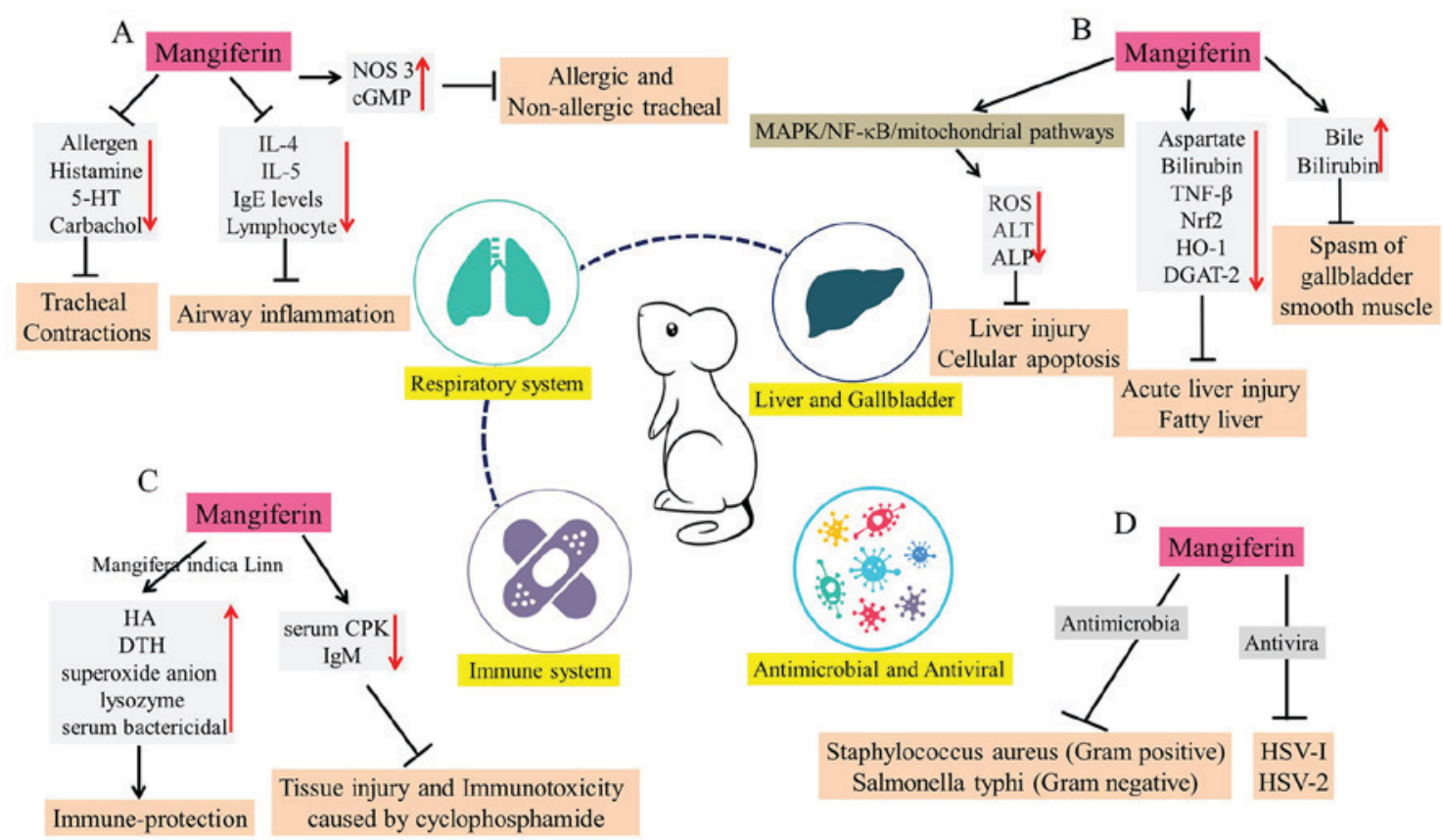

Figure 6. Overview of the various actions of mangiferin on (A) respiratory diseases, (B) liver and gallbladder disorders, (C) immunological abnormalities and (D) pathogenic microorganisms. 5-HT, 5-hydroxytryptamine; IL, interleukin; NOS 3, nitric oxide synthase 3; cGMP, cyclic guanosine monophosphate; MAPK, mitogen-activated protein kinase; NF- $\mathrm{BB}$, nuclear factor-кB; ROS, reactive oxygen species; ALT, alanine aminotransferase; ALP, alkaline phosphatase; TNF- $\beta$, tumor necrosis factor- $\beta$; Nrf2, nuclear factor, erythroid like 2; HO-1, heme oxygenase-1; DGAT-2, diacylglycerol O-acyltransferase 2; HSV, herpes simplex virus; CPK, creatine phosphokinase; HA, humoral antibody; DTH, delayed-type hypersensitivity; Ig, immunoglobulin.

endothelial cells (HUVECs) have been extensively demonstrated (Fig. 5C). It has been demonstrated that mangiferin $(20 \mu \mathrm{M})$ decreases high cellular permeability and endothelial injury induced by paraquat intoxication in HUVECs, through modulation of p120-catenin protein (92). In addition, cell survival increases in $\mathrm{H}_{2} \mathrm{O}_{2}$-treated HUVECs when mangiferin (10 and $20 \mu \mathrm{M}$ ) is administered, through its free-radical scavenging ability. A ferric reducing ability of plasma assay also demonstrated it antioxidant capacity (93). Similarly, incubation of HUVECs with glycated protein alone, or in combination with iron chelate, resulted in increased lipid peroxidation (LPO), accompanied by depletion of SOD, catalase, glutathione peroxidase and glutathione reductase levels. These data suggest that mangiferin $(5$ and $10 \mu \mathrm{M})$ has a protective effect against glycated protein-iron chelate-induced toxicity (94), which provides a promising perspective for the prevention of oxidative stress and toxicant-associated disease.

\section{Other properties of mangiferin}

Mangiferin is used to prepare medicinal and food supplements as a bioactive compound, where it may exert protective effects against neurodegenerative disease, cancer, obesity, cardiovascular disease and diabetes. However, mangiferin is also associated with other miscellaneous properties.

Mangiferin in respiratory system. Mangiferin exerts protective effects against bronchial asthma and other allergic diseases. Research has demonstrated that mangiferin inhibits tracheal contractions induced by distinct stimuli, including allergens, histamine, 5-hydroxytryptamine and carbachol, in a dose-dependent manner (95). The antispasmodic effect of mangiferin on allergic and non-allergic tracheal contraction of guinea pig tracheal rings are a result of increased intracellular levels of nitric oxide synthase 3 and cyclic GMP (95). In addition, in an allergic murine experimental model, mice were orally treated with $M$. indica extract $(50,100$ or $250 \mathrm{mg} / \mathrm{kg}$ ) or mangiferin $(50 \mathrm{mg} / \mathrm{kg})$ from day 0 to 24 . The results revealed that mangiferin produces a remarkable reduction in airway inflammation around vessels and bronchi, decreases immunoglobulin (Ig)E levels and lymphocyte proliferation. In addition, it was demonstrated that mangiferin inhibits IL-4 and IL-5 cytokine production in bronchoalveolar lavage fluid and lymphocyte culture supernatant (96). These experiments may be an important part of pre-clinical research that is necessary for the application of mangiferin in the treatment of respiratory diseases (Fig. 6A).

Mangiferin in liver and gallbladder disorders. Liver disease has become a major burden of human health (97). Gentiopicroside and mangiferin are regarded as two important medicinal monomers of Swertia mussotii, a herb used in Tibetan folk medicine. These may exert hepatoprotective and choleretic effects (Fig. 6B) $(98,99)$.

Pal et al (100) investigated the molecular mechanisms underlying the protective action of mangiferin against lead-induced liver injury and cellular apoptosis (100). It was revealed that mangiferin ( $100 \mathrm{mg} / \mathrm{kg}$, orally for 6 days) inhibits ROS production and reduces the levels of serum marker enzymes, such as ALT and ALP. Overall, it was demonstrated that mangiferin exhibits both antioxidative and antiapoptotic properties via MAPK/NF-kB/mitochondria-dependent pathways (100). 
Compared with silymarin, a standard hepatoprotective drug, the intraperitoneal pretreatment of mangiferin $(30 \mathrm{mg} / \mathrm{kg})$ possesses an extensive protective effect via reduction of serum aspartate and alanine aminotransferases, alkaline phosphatase, bilirubin and inflammatory mediator TNF- $\beta$ (101). These results suggest that mangiferin exhibits potent hepatoprotective effects on $\mathrm{CCl}$-4-induced liver damages in mice (101). In addition, in LPS and D-galactosamine (D-GalN)-induced acute liver injury, mangiferin upregulates the expression of Nrf2 and HO-1 in a dose-dependent manner. Furthermore, mangiferin markedly inhibits LPS/D-GalN-induced inflammatory factors, including IL-1 $\beta$, TNF- $\alpha$, NLRP3, apoptosis-associated speck-like protein containing a CARD and caspase-1 (102). Mangiferin treatment ameliorates fatty liver in fructose-fed spontaneously hypertensive rats (SHR) by inhibiting hepatic DGAT2, which catalyzes the final step of triglyceride biosynthesis (103). Mangiferin may enhance de novo fatty acid synthesis and oxidation in the treatment of fatty liver. Furthermore, the experiment of bile duct drainage in rats also demonstrated that mangiferin $(20 \mathrm{mg} / \mathrm{kg})$ markedly increases bile secretion and bilirubin content. In addition, gallbladder smooth muscle spasms are inhibited at a dose of $10 \mathrm{mg} / \mathrm{kg}$ (104).

Mangiferin and the immune system. The role of mangiferin in the immune system has gained increasing attention (Fig. 6C). Mangiferaindica (extract containing 2.6\% mangiferin) has been investigated for its immunoprotective effects, via increasing the frequency of delayed type hypersensitivity (DTH) reactions and the humoral antibody (HA) titer in mice (105). Similarly, mangiferin stimulates the immune systems and increases the resistance of Labeo rohita to Aeromonas hydrophila infection, by promoting superoxide anion, serum protein obtained from Labeo rohita and albumin production, as well as lysozyme and serum bactericidal activity (106). In order to compare the immunoprotective effects of mangiferin (the major polyphenol of Vimang) and VIMANG (an aqueous extract of Mangifera indica) on mouse antibody responses induced by inoculation with spores of microsporidian parasites, it was suggested that the components of Mangifera indica extracts may be of potential value for modulating the humoral response in different immunopathological disorders (107). However, VIMANG contains other extracts in addition to mangiferin polyphenol; therefore, the researchers may have neglected to take into account the inhibitory effects of other compounds isolated from VIMANG on the humoral response (107). In addition, mangiferin markedly suppresses tissue injury and immunotoxicity caused by cyclophosphamide treatment, through decreasing serum CPK activity and antigen-specific IgM levels (108). Thus, it was evident that mangiferin exerts an immunoprotective role via inhibition of reactive intermediate-induced oxidative stress in lymphocytes, neutrophils and macrophages (108). These data suggest that mangiferin has the potential to reduce the immunotoxicity of cyclophosphamide in oncotherapy.

The antimicrobial and antiviral effects of mangiferin. Anemarrhena asphodeloides, a plant widely used in traditional Chinese medicine, has been reported to possess antiviral and antibacterial activities (109). Mangiferin is the main effective component of Anemarrhena asphodeloides (109). In addition to its antioxidative, antidiabetic and antitumor properties, the antibacterial and antiviral effects of mangiferin are also prominent (110). Mangiferin has been demonstrated to exert antibacterial activity against two bacterial species: Staphylococcus aureus (Gram positive) and Salmonella typhi (Gram negative) (111). Through tissue culture techniques, the antiviral effects of mangiferin and isomangiferin on herpes simplex virus-1 (HSV-1) were demonstrated, with average plaque reduction rates of 56.8 and $69.5 \%$, respectively (112). The $\mathrm{EC}_{50}$ of mangiferin against herpes simplex virus-2 (HSV-2) plaque formation in HeLa cells was $111.7 \mathrm{mg}$, and the therapeutic index $\left(\mathrm{IC}_{50} / \mathrm{EC}_{50}\right)$ was 8.1 (113). Oral mangiferin $(50 \mathrm{mg} / \mathrm{kg})$ suppresses the growth of nematode Trichinella spiralis throughout the parasitic life cycle, by inhibiting mast cell degranulation, decreasing the serum levels of specific anti-Trichinella $\operatorname{IgE}$ and reducing the number of parasitic larvae (114). These studies confirm the antibacterial effects of isolated mangiferin, which may further processed as an antibacterial agent (Fig. 6D).

The main barrier for xenobiotic absorption through the skin is the stratum corneum. Research has revealed the ability of mangiferin to reversibly inhibit elastase and collagenase activity, as well as to permeate the stratum corneum and pass into the epidermis and dermis (115). As the fat and water distribution coefficient of mangiferin is relatively high, oral absorption is low (9), which suggests that mangiferin may be better absorbed through the skin.

\section{Conclusions}

Mangiferin has been demonstrated to possess several beneficial properties, including antioxidant, antimicrobial, antidiabetic, antiallergic, neuroprotective, cardiovascular protective, anticancer, hypocholesterolemic and immunomodulatory effects. Although it has been regarded as a compound with extensive pharmacological activity, the pharmacodynamics of mangiferin remain unclear. Mangiferin appears to have diverse pharmacological effects. However, further clinical research into the pharmacology and pharmacokinetics of mangiferin is required, as most of these effects have only been demonstrated in in vivo and in vitro experiments. The administration of mangiferin to animals or humans will inevitably result in alterations in the body, at the molecular, cellular, tissue and/or organs level, along with its curative effects. Therefore, genomic, proteomic and metabolomic analysis should be the main strategies utilized in order to determine the pharmacodynamics of mangiferin.

The research and development of mangiferin is expected to provide novel drugs for disease treatment. However, among the numerous studies on the pharmacology of mangiferin, researchers did not use a standardized therapeutic approach. Specifically, the pharmacodynamic indexes of mangiferin in existing researches, including dose, concentration and $\mathrm{IC}_{50}$, were not compared and analyzed at the same base line; therefore, the experimental results are not universal. Thus, the unified and standardized evaluation of the efficacy of mangiferin is a central component in the further exploration of pharmacodynamics and quality assurance. Furthermore, in the clinical research of mangiferin, researchers should focus on 
pharmacodynamic parameters caused by its physicochemical properties, including bioavailability, half-life, adverse reactions and toxicity. In addition, further clinical trials should be implemented to allow the broad application of this effective bioactive compound.

\section{Acknowledgements}

Not applicable.

\section{Funding}

This review was supported by the National Science Foundation of China (grant no. 81802504), the Sichuan National Science Research Funding (grant no. 2018JY0645) and Sichuan Health and Family Planning Commission Funding (grant no. 16ZD0253), and Dr. Yi Wang received funding from the Sichuan Provincial People's Hospital and a Sichuan Scientific Research Grant for Returned Overseas Chinese Scholars (grant no. 30305031014). The study was also supported by the National Key Specialty Construction Project of Clinical Pharmacy (grant no. 30305030698).

\section{Availability of data and materials}

Not applicable.

\section{Authors' contributions}

SD and HL wrote the manuscript. TL prepared the figures. $\mathrm{XX}, \mathrm{HW}$ and $\mathrm{XH}$ searched for the relevant literature. RT and YW reviewed and edited the manuscript. All authors have read and approved the manuscript.

\section{Ethics approval and consent to participate}

Not applicable.

\section{Patient consent for publication}

Not applicable.

\section{Competing interests}

The authors declare that they have no competing interests.

\section{References}

1. Dar A, Faizi S, Naqvi S, Roome T, Zikr-ur-Rehman S, Ali M, Firdous S and Moin ST: Analgesic and antioxidant activity of mangiferin and its derivatives: The structure activity relationship. Biol Pharm Bull 28: 596-600, 2005.

2. Duang XY, Wang Q, Zhou XD and Huang DM: Mangiferin: A possible strategy for periodontal disease to therapy. Med Hypotheses 76: 486-488, 2011.

3. Guha S, Ghosal S and Chattopadhyay U: Antitumor, immunomodulatory and anti-HIV effect of mangiferin, a naturally occurring glucosylxanthone. Chemotherapy 42: 443-451, 1996.

4. Ajila CM, Rao LJ and Rao UJ: Characterization of bioactive compounds from raw and ripe Mangifera indica L. peel extracts. Food Chem Toxicol 48: 3406-3411, 2010

5. Iseda S: On mangiferin, the coloring matter of mango (Mangifera indica Linn). V. Identification of sugar component and the structure of mangiferin. Bull Chem Soc Jpn 30: 629-633, 1957.
6. Wang Z, Deng J, Wang Q, Li X and Wei H: Improvement in the solubility of mangiferin by HP- $\beta-\mathrm{CD}$ inclusion. Chin Tradit Patent Med, 2008.

7. Han D, Chen C, Cong Z, Yu Z and Xing T: Determination of mangiferin in rat plasma by liquid-liquid extraction with UPLC-MS/MS. J Pharm Biomed Anal 51: 260-263, 2010.

8. Liu R, Liu Z, Zhang C and Zhang B: Gelucire44/14 as a novel absorption enhancer for drugs with different hydrophilicities: In vitro and in vivo improvement on transcorneal permeation. J Pharm Sci 100: 3186-3196, 2011.

9. Ma H, Chen H, Sun L, Tong L and Zhang T: Improving permeability and oral absorption of mangiferin by phospholipid complexation. Fitoterapia 93: 54-61, 2014.

10. Saleh F, Mumu SJ, Ara F, Hafez MA and Ali L: Non-adherence to self-care practices \& medication and health related quality of life among patients with type 2 diabetes: A cross-sectional study. BMC Public Health 14: 431, 2014.

11. Kueh YC, Morris T and Ismail AA: The effect of diabetes knowledge and attitudes on self-management and quality of life among people with type 2 diabetes. Psychol Health Med 22: 138-144, 2017.

12. Ogurtsova K, da Rocha Fernandes JD, Huang Y, Linnenkamp U, Guariguata L, Cho NH, Cavan D, Shaw JE and Makaroff LE: IDF diabetes atlas: Global estimates for the prevalence of diabetes for 2015 and 2040. Diabetes Res Clin Pract 128: 40-50, 2017.

13. Xu Y, Wang L, He J, Bi Y, Li M, Wang T, Wang L, Jiang Y, Dai M, Lu J, et al: Prevalence and control of diabetes in Chinese adults. JAMA 310: 948-959, 2013.

14. Barker A, Langenberg C and Wareham NJ: Genetic determinants of glucose homeostasis. Best Pract Res Clin Endocrinol Metab 26: 159-170, 2012.

15. Saltiel AR and Kahn CR: Insulin signalling and the regulation of glucose and lipid metabolism. Nature 414: 799-806, 2001.

16. Göke B: Islet cell function: Alpha and beta cells-partners towards normoglycaemia. Int J Clin Pract Suppl 62: 2-7, 2008.

17. Cusi K: The role of adipose tissue and lipotoxicity in the pathogenesis of type 2 diabetes. Curr Diab Rep 10: 306-315, 2010.

18. Scheen AJ: Pathophysiology of type 2 diabetes. Acta Clin Belg 58: 335-341, 2003.

19. Avogaro A, Giorda C, Maggini M, Mannucci E, Raschetti R, Lombardo F, Spila-Alegiani S, Turco S, Velussi $M$ and Ferrannini E; Diabetes and Informatics Study Group, Association of Clinical Diabetologists, Istituto Superiore di Sanità: Incidence of coronary heart disease in type 2 diabetic men and women: Impact of microvascular complications, treatment, and geographic location. Diabetes Care 30: 1241-1247, 2007.

20. Connelly K, Kelly D and Gilbert R: Clinically relevant models of diabetic cardiac complications. Circ Res 101: e78, 2007.

21. De Mattia G, Bravi MC, Laurenti O, Moretti A, Cipriani R, Gatti A, Mandosi E and Morano S: Endothelial dysfunction and oxidative stress in type 1 and type 2 diabetic patients without clinical macrovascular complications. Diabetes Res Clin Pract 79: 337-342, 2008.

22. Happich M, Breitscheidel L, Meisinger C, Ulbig M, Falkenstein P, Benter $U$ and Watkins J: Cross-sectional analysis of adult diabetes type 1 and type 2 patients with diabetic microvascular complications from a German retrospective observational study. Curr Med Res Opin 23: 1367-1374, 2007.

23. Cohen A and Horton ES: Progress in the treatment of type 2 diabetes: New pharmacologic approaches to improve glycemic control. Curr Med Res Opin 23: 905-917, 2007.

24. Carpino PA and Goodwin B: Diabetes area participation analysis: A review of companies and targets described in the 2008-2010 patent literature. Expert Opin Ther Pat 20: 1627-1651, 2010.

25. Sellamuthu PS, Arulselvan P, Fakurazi S and Kandasamy M: Beneficial effects of mangiferin isolated from Salacia chinensis on biochemical and hematological parameters in rats with streptozotocin-induced diabetes. Pak J Pharm Sci 27: 161-167, 2014.

26. Sellamuthu PS, Muniappan BP, Perumal SM and Kandasamy M: Antihyperglycemic effect of mangiferin in streptozotocin induced diabetic rats. J Health Sci 55: 206-214, 2009.

27. Saleh S, El-Maraghy N, Reda E and Barakat W: Modulation of diabetes and dyslipidemia in diabetic insulin-resistant rats by mangiferin: Role of adiponectin and TNF- $\alpha$. An Acad Bras Cienc 86: 1935-1948, 2014.

28. Muruganandan S, Srinivasan K, Gupta S, Gupta PK and Lal J: Effect of mangiferin on hyperglycemia and atherogenicity in streptozotocin diabetic rats. J Ethnopharmacol 97: 497-501, 2005.

29. Miura T, Iwamoto N, Kato M, Ichiki H, Kubo M, Komatsu Y, Ishida T, Okada $M$ and Tanigawa $K$ : The suppressive effect of mangiferin with exercise on blood lipids in type 2 diabetes. Biol Pharm Bull 24: 1091-1092, 2001. 
30. Miura T, Ichiki H, Hashimoto I, Iwamoto N, Kato M, Kubo M, Ishihara E, Komatsu Y, Okada M, Ishida T and Tanigawa K: Antidiabetic activity of a xanthone compound, mangiferin. Phytomedicine 8: 85-87, 2001.

31. Kumar SR, Ray MI, Ujwala M, Borde MK and Deshmukh YA: Natural dipeptidyl peptidase-IV inhibitor mangiferin mitigates diabetes- and metabolic syndrome-induced changes in experimental rats. Diabetes Metab Syndr Obes 9: 261-272, 2016.

32. Wang HL, Li CY, Zhang B, Liu YD, Lu BM, Shi Z, An N, Zhao LK, Zhang JJ, Bao JK and Wang Y: Mangiferin facilitates islet regeneration and $\beta$-cell proliferation through upregulation of cell cycle and $\beta$-cell regeneration regulators. Int J Mol Sci 15: 9016-9035, 2014

33. Duran-Salgado MB and Rubio-Guerra AF: Diabetic nephropathy and inflammation. World J Diabetes 5: 393-398, 2014

34. Pal PB, Sinha K and Sil PC: Mangiferin attenuates diabetic nephropathy by inhibiting oxidative stress mediated signaling cascade, $\mathrm{TNF} \alpha$ related and mitochondrial dependent apoptotic pathways in streptozotocin-induced diabetic rats. PLoS One 9 e107220, 2014

35. Liu YW, Zhu X, Zhang L, Lu Q, Wang JY, Zhang F, Guo H, Yin JL and Yin XX: Up-regulation of glyoxalase 1 by mangiferin prevents diabetic nephropathy progression in streptozotocin-induced diabetic rats. Eur J Pharmacol 721: 355-364, 2013

36. Zhu X, Cheng YQ, Du L, Li Y, Zhang F, Guo H, Liu YW and Yin XX: Mangiferin attenuates renal fibrosis through down-regulation of osteopontin in diabetic rats. Phytother Res 29: 295-302, 2015

37. Gaede P, Vedel P, Larsen N, Jensen GV, Parving HH and Pedersen O: Multifactorial intervention and cardiovascular disease in patients with type 2 diabetes. N Engl J Med 348: 383-393, 2003

38. Kannel WB and McGee DL: Diabetes and cardiovascular disease: The Framingham Study. JAMA 241: 2035-2038, 1979.

39. Manson JE, Colditz GA, Stampfer MJ, Willett WC, Krolewski AS, Rosner B, Arky RA, Speizer FE and Hennekens CH: A prospective study of maturity-onset diabetes mellitus and risk of coronary heart disease and stroke in women. Arch Intern Med 151: 1141-1147, 1991.

40. Ramasamy R, Yan SF and Schmidt AM: Receptor for AGE (RAGE): Signaling mechanisms in the pathogenesis of diabetes and its complications. Ann N Y Acad Sci 1243: 88-102, 2011

41. Suchal K, Malik S, Khan SI, Malhotra RK, Goyal SN Bhatia J, Kumari S, Ojha S and Arya DS: Protective effect of mangiferin on myocardial ischemia-reperfusion injury in streptozotocin-induced diabetic rats: Role of AGE-RAGE/MAPK pathways. Sci Rep 7: 42027, 2017.

42. Hou J, Zheng D, Fung G, Deng H, Chen L, Liang J, Jiang Y and $\mathrm{Hu} \mathrm{Y}$ : Mangiferin suppressed advanced glycation end products (AGEs) through NF- $\mathrm{kB}$ deactivation and displayed anti-inflammatory effects in streptozotocin and high fat diet-diabetic cardiomyopathy rats. Can J Physiol Pharmacol 94: 332-340, 2016.

43. Hou J, Zheng D, Zhong G and Hu Y: Mangiferin mitigates diabetic cardiomyopathy in streptozotocin-diabetic rats. Can J Physiol Pharmacol 91: 759-763, 2013.

44. Basha B, Samuel SM, Triggle CR and Ding H: Endothelial dysfunction in diabetes mellitus: Possible involvement of endoplasmic reticulum stress? Exp Diabetes Res 2012: 481840, 2012.

45. Song J, Li J, Hou F, Wang X and Liu B: Mangiferin inhibits endoplasmic reticulum stress-associated thioredoxin-interacting protein/NLRP3 inflammasome activation with regulation of AMPK in endothelial cells. Metabolism 64: 428-437, 2015.

46. Barascu A, Besson P, Le Floch O, Bougnoux P and Jourdan ML: CDK1-cyclin B1 mediates the inhibition of proliferation induced by omega-3 fatty acids in MDA-MB-231 breast cancer cells. Int J Biochem Cell Biol 38: 196-208, 2006.

47. Miyazaki T and Arai S: Two distinct controls of mitotic cdk1/cyclin B1 activity requisite for cell growth prior to cell division. Cell Cycle 6: 1419-1425, 2007.

48. Porter LA and Donoghue DJ: Cyclin B1 and CDK1: Nuclear localization and upstream regulators. Prog Cell Cycle Res 5 335-347, 2003.

49. Hu X and Moscinski LC: Cdc2: A monopotent or pluripotent CDK? Cell Prolif 44: 205-211, 2011.

50. Peng ZG, Yao YB, Yang J, Tang YL and Huang X: Mangiferin induces cell cycle arrest at G2/M phase through ATR-Chk1 pathway in HL-60 leukemia cells. Genet Mol Res 14: 4989-5002, 2015.

51. Yao YB, Peng ZG, Liu ZF, Yang J and Luo J: Effects of mangiferin on cell cycle status and CDC2/Cyclin B1 expression of HL-60 cells. Zhong Yao Cai 33: 81-85, 2010 (In Chinese).
52. du Plessis-Stoman D, du Preez J and van de Venter M: Combination treatment with oxaliplatin and mangiferin causes increased apoptosis and downregulation of $\mathrm{NF \kappa B}$ in cancer cell lines. Afr J Tradit Complement Altern Med 8: 177-184, 2011.

53. Dolcet X, Llobet D, Pallares J and Matias-Guiu X: NF-kB in development and progression of human cancer. Virchows Archiv 446: 475-382, 2005.

54. García-Rivera D, Delgado R, Bougarne N, Haegeman G and Berghe WV: Gallic acid indanone and mangiferin xanthone are strong determinants of immunosuppressive anti-tumour effects of Mangifera indica L. bark in MDA-MB231 breast cancer cells. Cancer Lett 305: 21-31, 2011.

55. Shi W, Deng J, Tong R, Yang Y, He X, Lv J, Wang H, Deng S, Qi P, Zhang D and Wang Y: Molecular mechanisms underlying mangiferin-induced apoptosis and cell cycle arrest in A549 human lung carcinoma cells. Mol Med Rep 13: 3423-3432, 2016.

56. Telang M, Dhulap S, Mandhare A and Hirwani R: Therapeutic and cosmetic applications of mangiferin: A patent review. Expert Opin Ther Pat 23: 1561-1580, 2013

57. Pomerantz JL and Baltimore D: Two pathways to NF-kappaB. Mol Cell. 10: 693-695, 2002.

58. Kawasaki H, Toyoda M, Shinohara H, Okuda J, Watanabe I, Yamamoto T, Tanaka K, Tenjo T and Tanigawa N: Expression of survivin correlates with apoptosis, proliferation, and angiogenesis during human colorectal tumorigenesis. Cancer 91: 2026-2032, 2001

59. Budihardjo I, Oliver H, Lutter M, Luo X and Wang X: Biochemical pathways of caspase activation during apoptosis. Annu Rev Cell Dev Biol 15: 269-290, 1999

60. Pan LL, Wang AY, Huang YQ, Luo Y and Ling M: Mangiferin induces apoptosis by regulating $\mathrm{Bcl}-2$ and $\mathrm{Bax}$ expression in the CNE2 nasopharyngeal carcinoma cell line. Asian Pac J Cancer Prev 15: 7065-7068, 2014

61. Kim H, Kim H, Mosaddik A, Gyawali R, Ahn KS and Cho SK Induction of apoptosis by ethanolic extract of mango peel and comparative analysis of the chemical constitutes of mango peel and flesh. Food Chem 133: 416-422, 2012.

62. Lv J, Wang Z, Zhang L, Wang HL, Liu Y, Li C, Deng J, Wang Y and Bao JK: Mangiferin induces apoptosis and cell cycle arrest in MCF-7 cells both in vitro and in vivo. J Anim Vet Adv 12: 352-359, 2013

63. Zou B, Wang H, Liu Y, Qi P, Lei T, Sun M and Wang Y: Mangiferin induces apoptosis in human ovarian adenocarcinoma OVCAR3 cells via the regulation of Notch3. Oncol Rep 38: 1431-1441, 2017.

64. Saha S, Sadhukhan P and Sil PC: Mangiferin: A xanthonoid with multipotent anti-inflammatory potential. Biofactors 42: 459-474, 2016.

65. Bera S, Chaudhuri S and Dutta D: Assessment of free-radical scavenging activities of mangiferin from Curcuma amada obtained by non-conventional extraction methods: A comparative study. Indian J Biotechnol 14: 179-185, 2015.

66. Abdul-Muneer PM, Chandra N and Haorah J: Interactions of oxidative stress and neurovascular inflammation in the pathogenesis of traumatic brain injury. Mol Neurobiol 51: 966-979, 2015.

67. Fujiwara N, Som AT, Pham LD, Lee BJ, Mandeville ET, Lo EH and Arai K: A free radical scavenger edaravone suppresses systemic inflammatory responses in a rat transient focal ischemia model. Neurosci Lett 633: 7-13, 2016.

68. Ren Y, Wei B, Song X, An N, Zhou Y, Jin X and Zhang Y: Edaravone's free radical scavenging mechanisms of neuroprotection against cerebral ischemia: Review of the literature. Int J Neurosci 125: 555-565, 2015 .

69. Lewén A, Matz P and Chan PH: Free radical pathways in CNS injury. J Neurotrauma 17: 871-890, 2000.

70. Fu Y, Liu H, Song C, Zhang F, Liu Y, Wu J, Wen X, Liang C, Ma K, Li L, et al: Mangiferin regulates cognitive deficits and heme oxygenase- 1 induced by lipopolysaccharide in mice. Int Immunopharmacol 29: 950-956, 2015.

71. Jangra A, Lukhi MM, Sulakhiya K, Baruah CC and Lahkar M: Protective effect of mangiferin against lipopolysaccharide-induced depressive and anxiety-like behaviour in mice. Eur J Pharmacol 740: 337-347, 2014.

72. Bhatia HS, Candelario-Jalil E, de Oliveira AC, Olajide OA, Martínez-Sánchez G and Fiebich BL: Mangiferin inhibits cyclooxygenase- 2 expression and prostaglandin $\mathrm{E} 2$ production in activated rat microglial cells. Arch Biochem Biophys 477: 253-258, 2008

73. Márquez L, García-Bueno B, Madrigal JL and Leza JC: Mangiferin decreases inflammation and oxidative damage in rat brain after stress. Eur J Nutr 51: 729-739, 2012 
74. Wang Z, Guo S, Wang J, Shen Y, Zhang J and Wu Q: Nrf2/HO-1 mediates the neuroprotective effect of mangiferin on early brain injury after subarachnoid hemorrhage by attenuating mitochondria-related apoptosis and neuroinflammation. Sci Rep 7: 11883, 2017.

75. Yang Z, Weian C, Susu H and Hanmin W: Protective effects of mangiferin on cerebral ischemia-reperfusion injury and its mechanisms. Eur J Pharmacol 771: 145-151, 2016.

76. Prabhu S, Jainu M, Sabitha KE and Devi CS: Role of mangiferin on biochemical alterations and antioxidant status in isoproterenol-induced myocardial infarction in rats. J Ethnopharmacol 107: 126-133, 2006.

77. Prabhu S, Jainu M, Sabitha KE and Devi CS: Cardioprotective effect of mangiferin on isoproterenol induced myocardial infarction in rats. Indian J Exp Biol 44: 209-215, 2006.

78. Prabhu S, Jainu M, Sabitha KE and Shyamala Devi CS: Effect of mangiferin on mitochondrial energy production in experimentally induced myocardial infarcted rats. Vascul Pharmacol 44: 519-525, 2006.

79. Prabhu S, Narayan S and Devi C: Mechanism of protective action of mangiferin on suppression of inflammatory response and lysosomal instability in rat model of myocardial infarction. Phytother Res 23: 756-760, 2009.

80. Zheng D, Hou J, Xiao Y, Zhao Z and Chen L: Cardioprotective effect of mangiferin on left ventricular remodeling in rats. Pharmacology 90: 78-87, 2012.

81. Arozal W, Suyatna FD, Juniantito V, Rosdiana DS, Amurugam S, Aulia R, Monayo ER and Siswandi R: The effects of mangiferin (Mangifera indica L) in doxorubicin-induced cardiotoxicity in rats. Drug Res (Stuttg) 65: 574-580, 2014.

82. Nordestgaard BG and Varbo A: Triglycerides and cardiovascular disease. Lancet 384: 626-635, 2014.

83. Nú?ez-Sellés Alberto J: Antioxidant therapy: myth or reality? J Braz Chem Soc 16: 699-710, 2005.

84.Pardo-Andreu GL, Paim BA, Castilho RF, Velho JA, Delgado R, Vercesi AE and Oliveira HC: Mangifera indica L: Extract (Vimang) and its main polyphenol mangiferin prevent mitochondrial oxidative stress in atherosclerosis-prone hypercholesterolemic mouse. Pharmacol Res 57: 332-338, 2008.

85. Guo F, Huang C, Liao X, Wang Y, He Y, Feng R, Li Y and Sun C: Beneficial effects of mangiferin on hyperlipidemia in high-fat-fed hamsters. Mol Nutr Food Res 55: 1809-1818, 2011.

86. Niu Y, Li S, Na L, Feng R, Liu L, Ying L and Sun C: Mangiferin decreases plasma free fatty acids through promoting its catabolism in liver by activation of AMPK. PLoS One 7: e30782, 2012

87. Na L, Zhang Q, Jiang S, Du S, Zhang W, Li Y, Sun C and Niu Y Mangiferin supplementation improves serum lipid profiles in overweight patients with hyperlipidemia: A double-blind randomized controlled trial. Sci Rep 5: 10344, 2015.

88. Apontes P, Liu Z, Su K, Benard O, Youn DY, Li X, Li W, Mirza RH, Bastie CC, Jelicks LA, et al: Mangiferin stimulates carbohydrate oxidation and protects against metabolic disorders induced by high-fat diets. Diabetes 63: 3626-3636, 2014.

89. Lim J, Liu Z, Apontes P, Feng D, Pessin JE, Sauve AA, Angeletti RH and Chi Y: Dual mode action of mangiferin in mouse liver under high fat diet. PLoS One 9: e90137, 2014.

90. Takagi A and Tada Y: Medical applicability of cultured vascular endothelial cells in cardiovascular surgery. Jpn J Cardiovasc Surg 19: 45-52, 1989.

91. Lahera V, Navarro-Cid J, Maeso R and Cachofeiro V: Participation of endothelium-derived vasoconstrictor factors in arterial hypertension. Rev Esp Cardiol 52 (Suppl 3): S4-S11, 1999 (In Spanish).

92.He Q, Ai J and Huang Y: Relationship between endothelial damage and p120-catenin in paraquat intoxication and the protective effect of mangiferin. Zhonghua Wei Zhong Bing Ji Jiu Yi Xue 26: 369-373, 2014 (In Chinese)

93. Luo F, Lv Q, Zhao Y, Hu G, Huang G, Zhang J, Sun C, Li X and Chen K: Quantification and purification of mangiferin from Chinese Mango (Mangifera indica L.) cultivars and its protective effect on human umbilical vein endothelial cells under $\mathrm{H}(2)$ O(2)-induced stress. Int J Mol Sci 13: 11260-11274, 2012.

94. Venugopal R, Sakthisekaran D, Rajkapoor B and Nishigaki I: In vitro protective effect of mangiferin against glycated protein-iron chelate induced toxicity in human umbilical vein endothelial cells. J Biol Sci 7: 1227-1232, 2007.

95. Vieira AB, Coelho LP, Insuela DB, Carvalho VF, dos Santos MH, Silva PM and Martins MA: Mangiferin prevents guinea pig tracheal contraction via activation of the nitric oxide-cyclic GMP pathway. PLoS One 8: e71759, 2013.
96. Rivera DG, Hernández I, Merino N, Luque Y, Álvarez A, Martín Y, Amador A, Nuevas L and Delgado R: Mangifera indica L. extract (Vimang) and mangiferin reduce the airway inflammation and Th2 cytokines in murine model of allergic asthma. J Pharm Pharmacol 63: 1336-1345, 2011.

97. Cohen JC, Horton JD and Hobbs HH: Human fatty liver disease. Old questions and new insights. Science 332: 1519-1523, 2011.

98. Guo Y and Xia C: Research progress of pharmacological action and clinical application in tibetan medicine 'Zangyinchen'. Asia Pac Tradit Med, 2016.

99. Tan L, Feng-Zu HU and Dong Q: Simultaneous determination of three iridoid glycosides and three flavonoids in Swertia mussotii Franch. from Qinghai by UPLC. Chin J Pharm Anal, 2017.

100. Pal PB, Sinha K and Sil PC: Mangiferin, a natural xanthone, protects murine liver in $\mathrm{Pb}(\mathrm{II})$ induced hepatic damage and cell death via MAP kinase, NF- $\kappa \mathrm{B}$ and mitochondria dependent pathways. PLoS One 8: e56894, 2013.

101. Rasool M, Sabina EP, Mahinda PS and Gnanaselvi BC: Mangiferin, a natural polyphenol protects the hepatic damage in mice caused by $\mathrm{CCl} 4$ intoxication. Comp Clin Pathol 21: 865-872, 2012

102. Pan CW, Pan ZZ, Hu JJ, Chen WL, Zhou GY, Lin W, Jin LX and Xu CL: Mangiferin alleviates lipopolysaccharide and D-galactosamine-induced acute liver injury by activating the Nrf2 pathway and inhibiting NLRP3 inflammasome activation. Eur J Pharmacol 770: 85-91, 2016.

103. Xing X, Li D, Chen D, Zhou L, Chonan R, Yamahara J, Wang J and Li Y: Mangiferin treatment inhibits hepatic expression of acyl-coenzyme A: Diacylglycerol acyltransferase-2 in fructose-fed spontaneously hypertensive rats: A link to amelioration of fatty liver. Toxicol Appl Pharmacol 280: 207-215, 2014.

104.He F, Zeng X, Wei G, Wen Y, Su H, Wei B, et al: Choleretic action and spasmolysis of gallbladder smooth muscle of mangiferin. China Pharmacist, 2014.

105. Makare N, Bodhankar S and Rangari V: Immunomodulatory activity of alcoholic extract of Mangifera indica L. in mice. J Ethnopharmacol 78: 133-137, 2001.

106. Sahu S, Das BK, Pradhan J, Mohapatra BC, Mishra BK and Sarangi N: Effect of Magnifera indica kernel as a feed additive on immunity and resistance to Aeromonas hydrophila in Labeo rohita fingerlings. Fish Shellfish Immunol 23: 109-118, 2007.

107. García D, Leiro J, Delgado R, Sanmartín ML and Ubeira FM: Mangifera indica L. extract (Vimang) and mangiferin modulate mouse humoral immune responses. Phytother Res 17: 1182-1187, 2003.

108. Muruganandan S, Lal J and Gupta PK: Immunotherapeutic effects of mangiferin mediated by the inhibition of oxidative stress to activated lymphocytes, neutrophils and macrophages. Toxicology 215: 57-68, 2005.

109. Miura T, Ichiki H, Iwamoto N, Kato M, Kubo M, Sasaki H, Okada M, Ishida T, Seino Y and Tanigawa K: Antidiabetic activity of the rhizoma of Anemarrhena asphodeloides and active components, mangiferin and its glucoside. Biol Pharm Bull 24: 1009-1011, 2001.

110. Kim CY, Ahn MJ and Kim J: Preparative isolation of mangiferin from anemarrhena asphodeloides rhizomes by centrifugal partition chromatography. J Liq Chromatogr Relat Technol 29: 869-875, 2006.

111. Maji HS, Maji S, Roy R, Sen A and Biswas T: Isolation of mangiferin from flowering buds of mangifera indica 1 and its evaluation of in vitro antibacterial activity. JPA 4: 49-56, 2015.

112. Zheng MS and Lu ZY: Antiviral effect of mangiferin and isomangiferin on herpes simplex virus. Chin Med J (Engl) 103: $160-165,1990$

113. Zhu XM, Song JX, Huang ZZ, Wu YM and Yu MJ: Antiviral activity of mangiferin against herpes simplex virus type 2 in vitro. Zhongguo Yao Li Xue Bao 14: 452-454, 1993 (In Chinese).

114. García D, Escalante M, Delgado R, Ubeira FM and Leiro J: Anthelminthic and antiallergic activities of Mangifera indica L. stem bark components Vimang and mangiferin. Phytother Res 17: 1203-1208, 2003.

115. Ochocka R, Hering A, Stefanowicz-Hajduk J, Cal K and Barańska H: The effect of mangiferin on skin: Penetration, permeation and inhibition of ECM enzymes. PLoS One 12: e0181542, 2017.

This work is licensed under a Creative Commons Attribution-NonCommercial-NoDerivatives 4.0 International (CC BY-NC-ND 4.0) License. 